\title{
Modifiable and non-modifiable epidemiological risk factors for acne, acne severity and acne scarring among Malaysian Chinese: a cross-sectional study
}

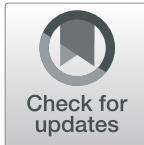

Yee-How Say ${ }^{1}$, Anna Hwee Sing Heng ${ }^{1}$, Kavita Reginald ${ }^{2}$, Yi Ru Wong², Keng Foo Teh², Smyrna Moti Rawanan Shah' ${ }^{2}$ Yang Yie Sio ${ }^{1}$, Yu Ting Ng${ }^{1}$, Sri Anusha Matta ${ }^{1}$, Sze Lei Pang ${ }^{1}$ and Fook Tim Chew ${ }^{1 *}$

\begin{abstract}
Background: Acne vulgaris, a highly prevalent multifactorial inflammatory skin disease, can be categorised into different severity and scarring grades based on the type, number, and severity of lesions. While many epidemiology studies have investigated the risk factors for acne presentation, fewer studies have specifically studied the risk factors for acne severity and scarring. Therefore, this study investigated the prevalence of acne, acne severity and scarring grades, and their associated non-modifiable and modifiable epidemiological risk factors among Malaysian Chinese.

Methods: A total of 1840 subjects (1117 cases/723 controls) completed an investigator-administered questionnaire as part of a cross-sectional study, which include socio-demographics, familial history, lifestyle factors, dietary habits, and acne history. Acne cases were further evaluated for their severity $(n=1051)$ and scarring $(n=1052)$ grades by a trained personnel.

Results: Majority of the acne cases (up to 69\%) had mild acne or Grade 1/2 scarring, while $21.6 \%$ had moderate/ severe acne and 5.5\% had Grade 3/4 scarring. Males had significantly higher risk of presenting with higher grades of acne scarring. Those who had acne, regardless of severity and scarring grades, had strong positive familial history (either in parents and/or sibling). Frequent consumption (most or all days) of foods that are commonly consumed during breakfast (butter, probiotic drinks, cereals and milk) decreased the risk for acne presentation and higher acne scarring, while periodic consumption (once/twice per week) of nuts and burgers/fast food decreased the risk for higher acne severity. Alcohol drinking was significantly associated with increased risk for acne presentation, while paternal, parental and household smoking were associated with reduced risk of more severe acne.

Conclusions: In conclusion, positive familial history is a strong predisposing factor in influencing acne presentation, severity and scarring. Frequent consumption of foods that are commonly consumed during breakfast is protective against acne presentation.
\end{abstract}

Keywords: Acne, Acne severity, Acne scarring, Dietary habits, Epidemiology, Risk factors

\footnotetext{
* Correspondence: dbscft@nus.edu.sg

'Department of Biological Sciences, Faculty of Science, National University of

Singapore, Allergy and Molecular Immunology Laboratory, Lee Hiok Kwee

Functional Genomics Laboratories, Block S2, Level 5, 14 Science Drive 4,

Lower Kent Ridge Road, Singapore 117543, Singapore

Full list of author information is available at the end of the article
}

(c) The Author(s). 2021 Open Access This article is licensed under a Creative Commons Attribution 4.0 International License, which permits use, sharing, adaptation, distribution and reproduction in any medium or format, as long as you give appropriate credit to the original author(s) and the source, provide a link to the Creative Commons licence, and indicate if changes were made. The images or other third party material in this article are included in the article's Creative Commons licence, unless indicated otherwise in a credit line to the material. If material is not included in the article's Creative Commons licence and your intended use is not permitted by statutory regulation or exceeds the permitted use, you will need to obtain permission directly from the copyright holder. To view a copy of this licence, visit http://creativecommons.org/licenses/by/4.0/ The Creative Commons Public Domain Dedication waiver (http://creativecommons.org/publicdomain/zero/1.0/) applies to the data made available in this article, unless otherwise stated in a credit line to the data. 


\section{Background}

Acne vulgaris (henceforth acne) is a chronic inflammatory skin disorder with a multifactorial pathogenesis. It is the eighth most common skin disease worldwide, with the 2010 Global Burden of Disease Study estimating a global prevalence of acne (for all ages) of 9.38\% [1]. However, in different countries and among different age groups, the prevalence of acne varies, with estimates ranging from $35 \%$ to close to $100 \%$ of adolescents having acne at some point [2]. Apart from the discomfort due to the clinical symptoms of acne, patients may experience other negative psychosocial impacts, like higher unemployment rates [3], increased depression and anxiety rates, lower self-esteem, and negative body image [4].

The pilosebaceous unit is well known as the site of acne development. The structure comprises the hair follicle and its connected sebaceous gland, which produces and secretes sebum onto the skin surface via the pore of the hair follicle [5]. Acne lesions develop when the pore of the pilosebaceous unit is blocked or inflamed [6]. The severity of acne is characterized by the number of noninflammatory closed and open comedones, and inflammatory pustules, papules, and nodules. Cysts, scars, erythema and hyperpigmentation could also be present in more severe acne [6]. For this reason, acne may be present in a wide variety of clinical forms depending on the type, number, and severity of the predominant lesions, and could be categorised into different severity [7] and scarring [8] grades.

The most notable pathophysiological factors that influence the development of acne are increased Cutibacterium acnes colonisation of the follicle, sebaceous gland hyperplasia with seborrhoea, abnormal desquamation of sebaceous follicle epithelium (comedogenesis), and, moreover, inflammatory and immunological reactions [5]. Recently, we reviewed that epidemiological risk factors influencing acne presentation and severity include non-modifiable factors like positive genetic predisposition or familial history, and hormonal factors attributed to gender and age; and modifiable factors like lifestyle factors (smoking, alcohol, physical activity) and dietary habits of certain food types/groups [9].

While many epidemiology studies have investigated the risk factors for acne presentation, fewer studies have specifically studied the risk factors for acne severity and acne scarring. To date, Malaysian studies studying acne have only investigated the influence of dietary habits $[10,11]$, or the impact of acne on the quality of life $[12,13]$. Therefore, this study investigated the prevalence of acne, acne severity and scarring grades, and their associated non-modifiable and modifiable epidemiological risk factors among Malaysian Chinese.

\section{Methods}

\section{Participants and data collection}

A cross-sectional study aimed to investigate the epidemiology of acne presentation, severity and scarring in a Malaysian Chinese population was conducted at Universiti Tunku Abdul Rahman (UTAR), Malaysia, in 2016 and 2018, and in Sunway University, Malaysia, in 2019. Due to the unequal percentages of the three main races, there may be a lower probability of sampling among Malays or Indians, which may lead to ascertainment bias. In the event of ascertainment bias, the results obtained from the epidemiological investigation may not be representative of certain racial groups in the population, making it difficult to interpret the results obtained. Further, ascertainment bias will lead to a loss of statistical power, affecting the quality of the results obtained. Dividing the sample population into racial subgroups for analysis was not practical, as the sample sizes for Malays and Indians were small, and there was a lack of statistical power for these comparisons. As such, only the majority racial group, the Chinese were included.

A validated investigator-administered questionnaire was adapted to collect information on demographics, personal and lifestyle habits, medical history, family history, dietary habits, socioeconomic status and acne history $[14,15]$ (Supplementary Information: Additional file 1). Particularly on the dietary habits, all the foods in question 37 of the original questionnaire [14] were included - except that cooked and raw vegetables, cereals and bread, fast foods and burgers were combined into single categories; olive oil, other dairy, sugar, fizzy/soft drinks were removed; Yakult ${ }^{\oplus} /$ Vitagen $^{\oplus} /$ similar yoghurt drinks was included. Ethical approval was granted from the Scientific and Ethical Review Committee (SERC) of UTAR (Ref. code: U/SERC/03/2016) and Sunway University Research Ethics Committee (Ref. code: SUREC 2019/029). All participants signed informed consent forms, and the study was conducted in accordance with the Declaration of Helsinki.

Participants were assessed for acne presentation and were classified as acne cases or controls using a definition designed to determine if participants have ever had acne. Acne cases had to fulfil at least one of four criteria: (1) they had ever visited a doctor for their acne condition; (2) they had scars (keloids) left by acne/boils; (3) they had moderate or severe acne; (4) they had Grade 3 or 4 scarring. Acne controls had to fulfil all of the following criteria: (1) they had never ever visited a doctor for their acne condition; (2) they never had scars (keloids) left by acne/boils; (3) they had no moderate or severe acne; (4) they had no grade 3 or 4 scarring. After excluding non-Malaysian Chinese, the total sample size was 1943, with 1117 acne cases and 723 acne controls. A total of 103 (5.3\%) individuals were excluded from both 
acne and acne severity analyses, as they did not fulfil the criteria to be classified as an acne case or an acne control.

A dedicated post-doctoral medical staff trained by a dermatologist assessed acne severity and scarring grades on a subset of acne cases, and assessment was crossvalidated by the dermatologist who turned up on selected days of collection and performed the assessment side-byside. There was no discrepancy between the assessments by the post-doctoral staff and dermatologist. Four categories were used for acne severity: (1) Nil, with $\leq 5$ comedones; (2) Mild, either (i) with $>5$ comedones and if inflammatory lesions are present, $<25$ total acne lesions (both inflammatory and non-inflammatory) or (ii) if only non-inflammatory lesions are present, the subject will be categorised as mild as long as there are $>5$ lesions regardless of number of total lesions present; (3) Moderate, with $\geq 25$ total acne lesions (both inflammatory and noninflammatory) and $\geq 1$ inflammatory lesion; and (4) Severe, either (i) with $\geq 30$ total acne lesions, including $\geq 3$ inflammatory lesions, affecting a large area of the face and or (ii) with $\geq 10$ inflammatory lesions regardless of area of face affected. This system was based on the Global Evaluation Acne (GEA) scale [7], with a few modifications. Firstly, as no participant fulfilled the criteria for grade 5 acne, we excluded grade 5 of the GEA scale from this study. Secondly, to make the grading more objective and reproducible, specific counts of non-inflammatory and inflammatory acne lesions were used to grade acne severity. Thirdly, due to the use of specific acne lesion counts, we removed the GEA scale criteria on the area of the face affected by acne lesions from our grading system.

Participants' acne scarring was classified into 5 scarring grades: (1) Grade 0, or no acne scars; (2) Grade 1, with shallow scars not visible from a distance affecting less than one quarter of the face; (3) Grade 2, with slightly deeper scars that are slightly visible from a distance affecting more than one quarter but less than half of the face; (4) Grade 3, with even deeper scars visible from a distance affecting at least half of the face; and (5) Grade 4, with the deepest scars that are clearly visible from a distance affecting almost the entire face. This grading system was adapted from the Qualitative Global Scarring Grading System (QGS [8];) and a few changes were made to make the system more suitable for an epidemiological setting. Firstly, unlike grade 1 of the QGS, we did not consider erythema or hyperpigmentation marks in our acne scar grading system, as these types of marks often diminish and disappear with time [8]. Further, as erythema and hyperpigmentation marks on the face may appear due to causes other than acne [16], such marks were excluded from our grading system. Another change made to the QGS was the consideration of the surface area of the face affected by the scars. This additional criterion was added to reduce the number of patients that fall between two scarring grades.

\section{Statistical analysis}

The data was cleaned by removing any invalid or inconsistent responses, and then analysed using the $\mathrm{IBM}^{\circ}$ SPSS $^{\circ}$ Statistics software (IBM Inc., NY). Binary logistic regression was used to model the association between acne presentation and potential risk factors. For acne severity comparisons, moderate and severe acne were combined into a single category for analysis due to the small sample size for severe acne. Univariate analyses were first conducted, followed by multivariate analyses adjusting for age and gender. For multivariate adjustment, subjects were categorised into three groups for age $(\leq 19,20-24$ and $>24$ years old $)$ and two groups for sex (male, female). Results were presented as odds ratios (OR) with 95\% confidence intervals (CI). Statistical significance of results was defined as $p<0.05$.

\section{Results \\ Prevalence of acne, acne severity grades and acne scarring grades}

The distribution of demographic characteristics of the sampled population is presented in Table 1. Participants

Table 1 Demographic characteristics of acne cases and controls and prevalence of severity and scarring grades among acne cases

\begin{tabular}{lcl}
\hline Variable & Case $(\boldsymbol{n}=\mathbf{1 1 1 7})$ & Control $(\boldsymbol{n}=\mathbf{7 2 3})$ \\
\hline Gender & $374(33.5)$ & $228(31.5)$ \\
Male & $743(66.5)$ & $494(68.3)$ \\
Female & $0(0.0)$ & $1(0.1)$ \\
Not stated & & \\
Age & $56(5.0)$ & $52(7.2)$ \\
$>24$ & $749(67.1)$ & $463(64.0)$ \\
20 to 24 & $312(27.9)$ & $207(28.6)$ \\
$\leq 19$ & $0(0.0)$ & $1(0.1)$ \\
Not stated & \\
Acne severity grades $(\boldsymbol{n}=\mathbf{1 0 5 1 )}$ & \\
Nil (no current acne) & $97(9.2)$ & \\
Mild & $727(69.2)$ & \\
Moderate & $224(21.3)$ & \\
Severe & $3(0.3)$ & \\
Acne scarring grades $(\boldsymbol{n}=\mathbf{1 0 5 2})$ & \\
Grade 0 (no current scars) & $317(30.1)$ \\
Grade 1 & $431(41.0)$ \\
Grade 2 & $246(23.4)$ \\
Grade 3 & $57(5.4)$ & \\
Grade 4 & $1(0.1)$ & \\
\hline
\end{tabular}

Values are frequencies (\%) 
were aged between 17 and 77 years (median $=21$ years, \pm $\mathrm{SD} 4.926 ; \mathrm{M} / \mathrm{F}=1: 2.2$ ) and the overall prevalence of acne in the sampled population was $60.7 \%$ (males: $33.5 \%$, females: $66.5 \%)$. Acne prevalence was the highest among those aged 20 to 24 , followed by $\leq 19$ and $>24$. There was no significant difference in acne case/control distribution between genders $\left(x^{2}=0.722 ; p=0.396\right)$ or age groups $\left(x^{2}=4.232 ; p=0.12\right)$. Among the 1117 cases, 1051 and 1052 individuals underwent assessment for acne severity and acne scarring, respectively. Among those assessed, 9.2 and $30.1 \%$ had no current acne or current scars and were excluded from severity and scarring analyses, respectively (Table 1). Majority of the acne cases (up to 69\%) had mild acne severity and grade 1 scarring, while less than $6 \%$ had higher grades of acne severity or scarring (severe or grade 3 and 4 scarring).

\section{Familial history is a strong predisposing risk factor for} acne presentation, while frequent butter and probiotic drink consumption reduces risk of acne

The risk factors that are significantly associated with acne presentation are presented in Table 2. A positive familial history of acne was strongly associated with increased odds for acne presentation, even after controlling for age and gender. Higher risk for acne was observed in individuals with a maternal, paternal, sibling, or at least one parent/sibling with history of acne, compared to those without familial history. Furthermore, when maternal and paternal familial history were analysed together as parental familial history, it was observed that having only one parent with acne increased the odds of acne to 3.663 (Table 2), while having both parents with acne increased the odds of acne to 3.509 (Table 2), suggesting that maternal and paternal familial history did not show additive effects.

Apart from familial history, age and household number were two socio-demographic factors significantly associated with acne presentation. The risk for acne was significantly higher in those aged 20-24 relative to those $>24$, and in those who came from a household with numbers $\geq 2$ relative to those $<2$ (Table 2). The significant association between household number and acne presentation remained even after further correction for parental acne, (adjusted OR $=2.092$, 95\% CI: 1.020 4.292, $p=0.044$ for 2-4 household numbers; adjusted $\mathrm{OR}=2.247,95 \%$ CI: $1.105-4.566, p=0.025$ for $>4$ household numbers), suggesting that household number was associated with acne presentation independent of familial history.

In addition, several lifestyle factors and dietary habits were associated with acne presentation risk. Higher acne risk was found in alcohol drinkers relative to nondrinkers (Table 2). In contrast, lower acne risk was noted in those who consumed butter or drank probiotic drinks on most or all days in the week, relative to those who never or only occasionally did that (Table 2). This suggests a possible protective effects against acne for those who consumed butter and probiotic drinks frequently.

Aside from the above, no significant association with acne presentation was observed for other evaluated factors, including gender, co-morbidities (overweight/obesity, atopy, asthma, rhinitis, eczema, atopic diseases and polycystic ovarian syndrome, PCOS), sedentary lifestyle (increased TV/computer usage and lack of physical activity) and dietary habits of other food groups/type [like meat, fruits, vegetables and high glycaemic index (GI) food; data not shown].

Familial history strongly influences both lower and higher acne severities and scarring grades compared to controls

As positive familial history of acne was strongly associated with increased risk for acne presentation, we sought to determine whether the same phenomenon could be seen for acne severity and scarring grades. When higher acne severity and scarring grades were compared against lower grades (moderate/severe vs. mild; grade $3 / 4$ vs. grade $1 / 2$ ), no significant association with familial history of acne was found (except for parental history; data not shown). However, when acne severity and scarring grades were compared against acne controls, strong significant association with maternal, paternal and sibling acne history was found (Table 3). This indicates that those who had acne, regardless of severity and scarring grades, also had a familial history of acne. Furthermore, when maternal and paternal familial history were analysed together as parental familial history, it was observed that having only one parent with acne increased the odds of grade $3 / 4$ acne scarring to 14.925 (Table 3), while having both parents with acne increased the odds of acne to 5.848 (Table 3). Similarly, when parental and sibling familial history were analysed together as familial acne, it was observed that having only one parent/sibling with acne increased the odds of lower acne severity and scarring grades (mild and grade 1/2) to 4.695 and 4.310, and decreased the odds of higher acne severity and scarring grades (severe and grade 3/4) to 3.185 and 6.993, respectively. This suggests that maternal and paternal familial history showed stepwise, additive effects - while sibling history showed stepwise, decrescent effect - on the risk of grade $3 / 4$ acne scarring relative to acne controls.

Household smoking is a determinant of acne severity, while dietary habits of breakfast food components affect acne scarring extent

Of the lifestyle factors evaluated, smoking and alcohol drinking habits affected acne severity risk. Interestingly, 
Table 2 Association of selected familial history, co-morbidities and lifestyle habits with acne presentation

\begin{tabular}{|c|c|c|c|c|}
\hline \multirow[t]{2}{*}{ Variable } & Unadjusted & \multirow[t]{2}{*}{$p$} & Adjusted $^{\mathrm{a}}$ & \multirow[t]{2}{*}{$p$} \\
\hline & OR $(95 \% \mathrm{Cl})$ & & \multirow{2}{*}{\multicolumn{2}{|c|}{ OR $(95 \% \mathrm{Cl})$}} \\
\hline \multicolumn{3}{|c|}{ A. Socio-demographic factors } & & \\
\hline \multicolumn{5}{|l|}{ Age } \\
\hline$>24$ & 1.00 & - & 1.00 & - \\
\hline $20-24$ & $1.502(1.012-2.227)$ & $0.043^{*}$ & 1.499 (1.009-2.222) & $0.045^{*}$ \\
\hline$\leq 19$ & $1.401(0.923-2.123)$ & 0.114 & $1.397(0.921-2.119)$ & 0.116 \\
\hline \multicolumn{5}{|l|}{ Household number } \\
\hline$\leq 2$ & 1.00 & - & 1.00 & - \\
\hline $2-4$ & $2.037(1.172-3.534)$ & $0.012^{*}$ & $1.894(1.079-3.322)$ & $0.026^{*}$ \\
\hline$>4$ & $2.146(1.247-3.690)$ & $0.006^{* *}$ & $1.984(1.136-3.460)$ & $0.016^{*}$ \\
\hline \multicolumn{5}{|l|}{ B. Familial history } \\
\hline \multicolumn{5}{|l|}{ Maternal Acne } \\
\hline Yes & $2.872(2.253-3.660)$ & $<0.001^{* * *}$ & $2.861(2.239-3.655)$ & $<0.001^{* * *}$ \\
\hline No & 1.00 & - & 1.00 & - \\
\hline \multicolumn{5}{|l|}{ Paternal Acne } \\
\hline Yes & $3.314(2.555-4.298)$ & $<0.001^{* * *}$ & $3.319(2.553-4.315)$ & $<0.001^{* * *}$ \\
\hline No & 1.00 & - & 1.00 & - \\
\hline \multicolumn{5}{|l|}{ Parental Acne } \\
\hline None & 1.00 & - & 1.00 & - \\
\hline Only 1 parent & $3.559(2.494-5.076)$ & $<0.001^{* * *}$ & $3.663(2.564-5.236)$ & $<0.001^{* * *}$ \\
\hline Both & $3.497(2.618-4.651)$ & $<0.001^{* * *}$ & $3.509(2.625-4.717)$ & $<0.001^{* * *}$ \\
\hline \multicolumn{5}{|l|}{ Sibling Acne } \\
\hline Yes & $3.187(2.544-3.992)$ & $<0.001^{* * *}$ & $3.167(2.527-3.968)$ & $<0.001^{* * *}$ \\
\hline No & 1.00 & - & 1.00 & - \\
\hline \multicolumn{5}{|l|}{ Familial Acne } \\
\hline None & 1.00 & - & 1.00 & - \\
\hline At least 1 parent/sibling & $4.184(3.279-5.348)$ & $<0.001^{* * *}$ & 4.202 (3.289-5.348) & $<0.001^{* * *}$ \\
\hline \multicolumn{5}{|l|}{ C. Lifestyle factors } \\
\hline \multicolumn{5}{|l|}{ Alcohol drinking } \\
\hline Non-drinker & 1.00 & - & 1.00 & - \\
\hline Drinker & $1.292(1.071-1.560)$ & $0.008^{* *}$ & $1.264(1.045-1.529)$ & $0.016^{*}$ \\
\hline \multicolumn{5}{|l|}{ D. Dietary habits } \\
\hline \multicolumn{5}{|l|}{ Butter consumption } \\
\hline Never/ occasionally & 1.00 & - & 1.00 & - \\
\hline Once or twice/week & $0.917(0.724-1.163)$ & 0.476 & $0.912(0.717-1.157)$ & 0.446 \\
\hline Most or all days & $0.672(0.460-0.983)$ & $0.041^{*}$ & $0.666(0.455-0.975)$ & $0.036^{*}$ \\
\hline \multicolumn{5}{|c|}{ Probiotic drink consumption } \\
\hline Never/ occasionally & 1.00 & - & 1.00 & - \\
\hline Once or twice/week & $1.189(0.931-1.520)$ & 0.165 & $1.185(0.926-1.515)$ & 0.178 \\
\hline Most or all days & $0.723(0.523-0.999)$ & $0.049^{*}$ & $0.701(0.506-0.973)$ & $0.034^{*}$ \\
\hline
\end{tabular}

Values are odds ratio $(95 \% \mathrm{Cl})$

${ }^{*} p<0.05 * * p \leq 0.009 * * * 0 \leq 0.000$

${ }^{a}$ Adjusted for age and gender 
Table 3 Association of familial history with lower and higher grades of acne severity grades and scarring

\begin{tabular}{|c|c|c|c|c|}
\hline \multirow[t]{3}{*}{ Variable } & \multicolumn{2}{|l|}{ Acne severity } & \multicolumn{2}{|l|}{ Acne scarring } \\
\hline & Mild vs. controls & Moderate/severe vs. controls & Grade $1 / 2$ vs. controls & Grade $3 / 4$ vs. controls \\
\hline & OR $(95 \% \mathrm{Cl})$ & OR $(95 \% \mathrm{Cl})$ & OR $(95 \% \mathrm{Cl})$ & OR $(95 \% \mathrm{Cl})$ \\
\hline \multicolumn{5}{|l|}{ Maternal Acne } \\
\hline Yes & $2.953(2.261-3.856)$ & $2.792(1.925-4.049)$ & $3.068(2.347-4.012)$ & $3.941(2.034-7.636)$ \\
\hline No & 1.00 & 1.00 & 1.00 & 1.00 \\
\hline \multicolumn{5}{|l|}{ Paternal Acne } \\
\hline Yes & $3.703(2.788-4.919)$ & $2.611(1.760-3.875)$ & $3.642(2.732-4.854)$ & $4.143(2.135-8.042)$ \\
\hline No & 1.00 & 1.00 & 1.00 & 1.00 \\
\hline \multicolumn{5}{|l|}{ Parental Acne } \\
\hline None & 1.00 & 1.00 & 1.00 & 1.00 \\
\hline Only 1 parent & $3.509(2.375-5.208)$ & $3.937(2.326-6.667)$ & $4.032(2.717-5.952)$ & $14.925(6.135-35.714)$ \\
\hline Both & $3.802(2.778-5.236)$ & $3.106(1.984-4.854)$ & $3.774(2.740-5.208)$ & $5.848(2.481-13.889)$ \\
\hline \multicolumn{5}{|l|}{ Sibling Acne } \\
\hline Yes & $3.507(2.722-4.520)$ & $2.521(1.746-3.639)$ & $3.372(2.607-4.360)$ & $6.021(2.748-13.193)$ \\
\hline No & 1.00 & 1.00 & 1.00 & 1.00 \\
\hline \multicolumn{5}{|l|}{ Familial Acne } \\
\hline None & 1.00 & 1.00 & 1.00 & 1.00 \\
\hline At least 1 parent/sibling & $4.695(3.546-6.211)$ & $3.185(2.128-4.762)$ & $4.310(3.257-5.714)$ & 6.993 (2.890-16.949) \\
\hline
\end{tabular}

All results were from multivariate analysis on familial history, adjusted fro age and gender All OR have significance of $p<0.001$

a few of the smoking variables studied were associated with reduced risk for more severe acne. Higher risk for moderate-severe acne was observed in individuals without paternal, parental or household smokers compared to the individuals with those (Table 4), suggesting that having family members who were smokers was associated with a reduced risk of moderate/severe acne. Similarly, having a maternal smoker was associated with a reduced risk of grade 3/4 acne scarring (Table 4). In contrast, other smoking variables studied - personal smoking status and passive smoking - showed no significant association with acne severity and scarring. Alcohol drinking habit was significantly associated with increased risk for higher grades of acne scarring, but this association was abolished after controlling for age and gender (Table 4).

In addition, dietary habits of certain food groups/types were also associated with protective effects for moderate/severe or grade 3/4 acne. Consumption of nuts and burgers/fast food once/twice per week was associated with lower risk for higher acne severity, while more frequent consumption (once/twice per week and above) of cereals, butter and milk (which seems to be food components commonly consumed during breakfast) was associated with lower risk for higher acne scarring (Table 4). Lower odds ratios of down to 0.26 were seen for consumption of cereals and milk for most or every day of the week, suggesting that frequent consumption of cereals with milk for breakfast particularly reduces the risk for higher acne scarring. Further comparison between acne grade $3 / 4$ vs. acne controls similarly replicated this significant association; with adjusted OR of 0.240 (95\% CI: $0.091-0.637 ; p=0.004$ ) and 0.129 (95\% CI: $0.017-0.983 ; p=0.048$ ) for consumption of milk and butter for most or every day of the week, respectively.

Apart from that, being male, underweight and having current asthma were associated with higher grades of acne scarring (Table 4). Further comparison between acne grade $3 / 4$ vs. acne controls also replicated the significant increase in higher acne scarring risk among males (adjusted OR $=3.411 ; 95 \%$ CI: $1.958-5.944 ; p<$ 0.001 ) and underweights (adjusted $\mathrm{OR}=2.160 ; 95 \% \mathrm{CI}$ : $1.053-4.425 ; p=0.036)$.

\section{Discussion}

In the Malaysian Chinese studied, the prevalence of acne was $60.7 \%$, lower than the prevalence among similar studies in Malaysia among Chinese adolescents $(72.5 \%$ [12];) and medical students (68.1\% [13];). The observed prevalence of moderate/severe acne $(21.6 \%)$ and acne scarring $(69.9 \%)$ was higher than the prevalence in previous Malaysian studies (9.8\% [12]; and 9.3\% [13]; for moderate/severe acne; $59 \%$ for acne scarring, [13]). Finally, while we did not find the male gender as a predisposing risk factor for acne presentation and severity unlike previous Malaysian studies [12, 13], we found that 


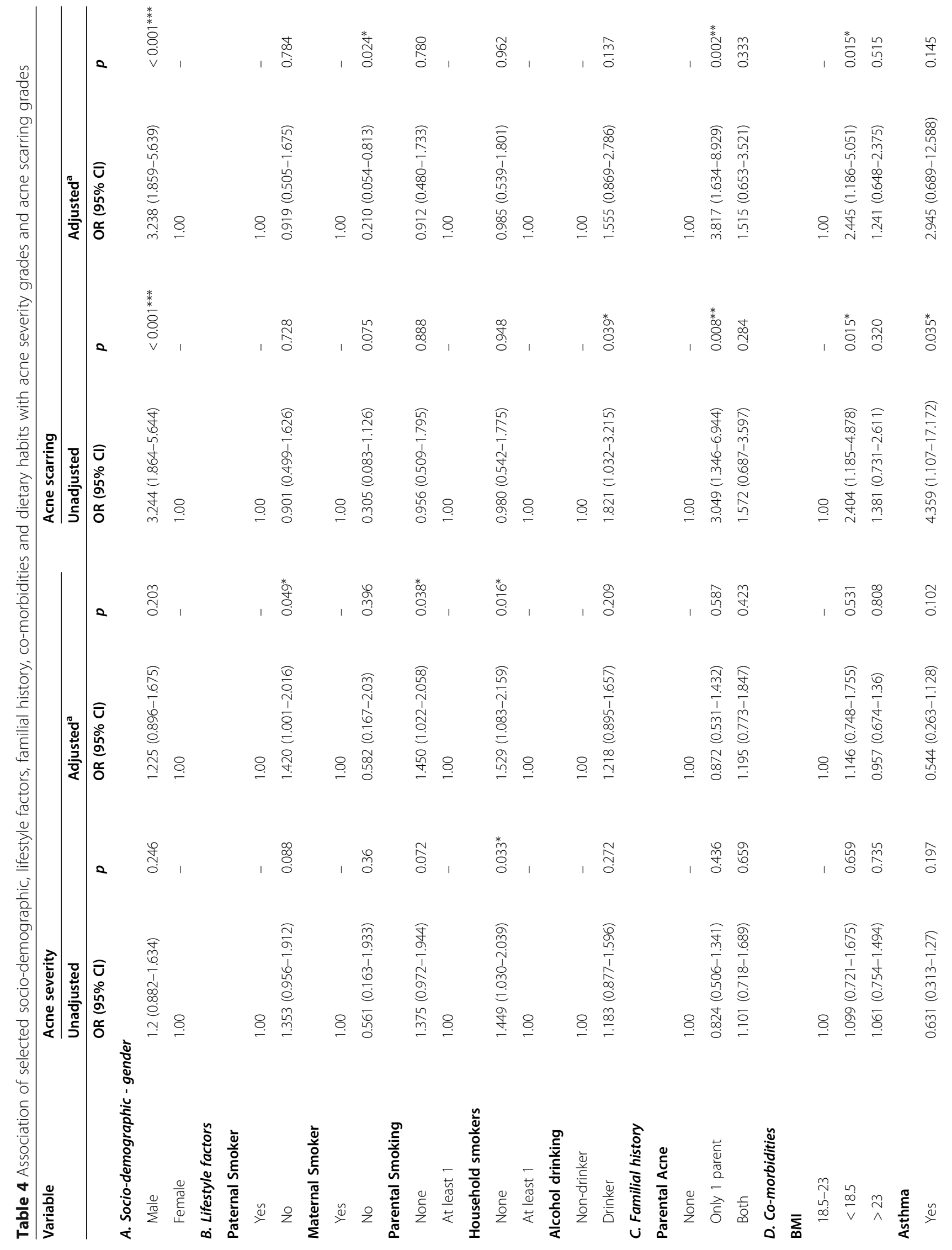




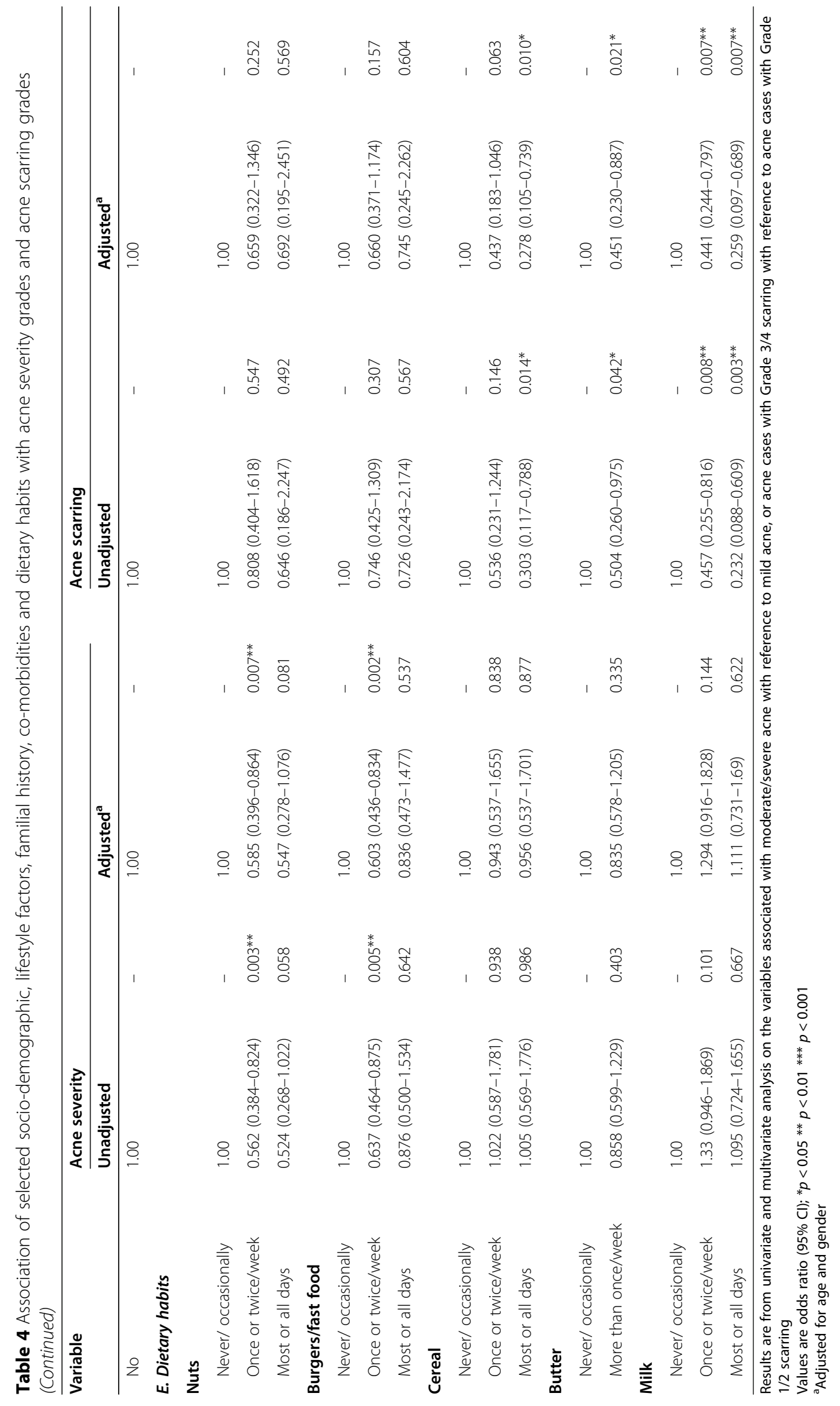


males had an increased risk for higher grades of acne scarring.

In this study, we found that those who had acne, regardless of severity and scarring grades, had strong positive familial history (either in parents and/or sibling). This proves that acne is a highly heritable trait. Recent genome-wide association studies (GWAS) and candidate gene association studies have identified that genetics, particularly gene variations, play a strong role in acne pathogenesis by modulating biological pathways like androgen metabolism, inflammation, stem cell fate and tissue remodelling (reviewed in [17]). Familial history did not show an additive effect for acne presentation; but for higher grades of acne scarring, maternal and paternal familial history showed stepwise, additive effects, while sibling history showed the opposite effect. However, in another Malaysian study, while maternal and paternal acne history significantly contributed to odds for developing acne (1.752 and 1.852, respectively), parental history showed an additive effect as the odds was increased to 3.056 [13]. Our recent meta-analysis found a pooled odds ratio of 2.91 (95\% CI 2.58-3.28; familial history in parents with reference to no familial history in parents [9]); for acne presentation. However, the association between familial history and acne severity and scarring is unclear; some studies reported a higher prevalence of severe acne grade in those with a positive familial history of acne [18], while others did not [19-21].

Dietary habits of certain food types/group seemed to decrease the risk for acne presentation, severity and scarring. Frequent consumption (most or all days) of foods that are commonly consumed during breakfast (butter, probiotic drinks, cereals and milk) decreased the risk for acne presentation and higher acne scarring, while periodic consumption (once/twice per week) of nuts and burgers/fast food decreased the risk for higher acne severity. This seems to indicate that having breakfast that is composed of those food components reduced acne presentation and higher scarring grade risks among Malaysian Chinese. In contrast, Ismail et al. [10] found that the consumption of milk $\geq$ once a week increased the risk of acne occurrence by 4 times (OR = 3.99, $95 \% \mathrm{CI}=1.39-11.43$ ) in a predominantly Malay Malaysian study, while Suppiah et al. [11] found that milk consumption was significantly higher $(\mathrm{OR}=2.19$, $95 \% \mathrm{CI}=1.04-4.65)$ among acne cases in a predominantly Chinese Malaysian study. The potential link between diet and acne presentation has been widely debated, with some studies finding no significant diet-acne link and others reporting that the intake of certain foods is associated with acne presentation (reviewed in [9]). For example, several studies found that frequent consumption of certain dairy products [22-24], carbohydrates, high GI and glycaemic load (GL) diet [25-27] is a potential risk factor for acne, which could be attributed partly to the insulin-like growth factor 1 (IGF1)/FoxO1/ mTORC1 signalling pathway. Meanwhile, high adherence to a Mediterranean diet - characterised by an omega-3 rich, low-GI diet - was associated with a protective effect against acne, possibly by anti-inflammatory and anti-IGF1 mechanisms [28]. Probiotic use, either through topical or oral administration, has been shown to inhibit acne pathogenesis by directly inhibiting $C$. acnes through the production of antibacterial proteins or through anti-inflammatory immunomodulatory effects (reviewed in [29]). However, neither earlier Malaysian studies found significant association between yoghurt intake and acne risk $[10,11]$. Taken together, since Jung et al. [30] showed that controls had higher regular breakfast intake compared to acne patients among Koreans, this indicates that regular breakfast intake - probably composing of butter, probiotic drink, cereals and milk as shown in this study - helps in reducing risk for acne presentation and higher acne scarring.

A few smoking variables - having a father who smokes, having at least one smoking parent and living in a household with at least one smoker - were associated with reduced risk of more severe acne in this Malaysian Chinese population. However, other smoking variables personal smoking status and passive smoking - were not associated with acne severity, similar with an earlier Malaysian study [11]. We recently reviewed that the link between smoking and acne severity is controversial, with inconsistent results between studies [9]. Rombouts et al. [31] observed that smoking was linked to decreased acne risk in girls, while smoking was found to be a risk factor for acne [20] and severe acne occurred more frequently among smokers [32]. Studies also considered smoking duration and number of cigarettes smoked - one study observed a significant dose-dependent relationship between acne severity and the number of cigarettes smoked per day [33], another did not [31]. The complex way in which smoking influences the pathogenesis of acne including inflammation, wound healing and immune responses [31], may contribute, in part, to these inconclusive evidences.

In this study, we found that alcohol drinking was significantly associated with increased risk for acne presentation and higher grades of acne scarring, but the latter association was abolished after controlling for age and gender. In our recent review, alcohol intake is consistently not significantly associated with acne risk [9], as shown by majority negative previous findings $[18,33-36]$.

BMI, sedentary lifestyle (assessed via computer/television usage), atopy, asthma, allergic rhinitis, eczema, atopic diseases and PCOS were not significantly associated with acne presentation in this Malaysian 
Chinese population. Nevertheless, being underweight was associated with increased risk of having higher grades of acne scarring, contrasting the findings of previous studies that reported higher acne prevalence in overweight individuals [18-20, 37-39]. However, an earlier Malaysian study found no significant association between BMI and acne presentation [10]. We also reported that having current asthma is a predisposing risk factor for higher grades of acne scarring, similar with the finding by Silverberg and Silverberg [40] which reported a significant association of severe acne with asthma.

Finally, age and household number were significantly associated with acne risk among Malaysian Chinese. Previous reports have observed highest acne prevalence among older teenagers and young adults and lower acne prevalence among older adults [41], which is in line with the results obtained in this study that demonstrate a higher risk of acne in those aged $20-24$ relative to those $>24$. None of the studies reviewed by us recently [9] investigated the association between household number and acne risk; thus, further studies are needed to understand the true relationship between the two.

We acknowledge a few limitations in our study. First, as the study subjects were Chinese university students and staff, the findings of this study could not be extrapolated to the multi-ethnic Malaysian population. Next, due to the retrospective crosssectional study design used, it could only determine the differences within a population between those who have developed acne and those who have not. It was also only able to determine the association, but not the cause and effect of the modifiable risk factors on acne. Also, following the removal/addition of some list of foods in the questionnaire, we have not performed a reliability and validity calibration assessment. Nevertheless, removal/addition of foods is actually recommended by the original questionnaire designers in order to make it more relevant for a particular country [14]. Apart from the three-level food frequency questionnaire used in this study, more frequency levels, more commonly-consumed food types, or even a repeated three-day food dairy (two weekdays and one weekend) could be adopted. Other psychosocial factors contributing to - or impacted from acne - like quality of life [12,13], stress, depression, anxiety, and sleep quality, could be taken into account in future studies. Despite these limitations with sample size of almost 2000 subjects - we have evaluated a wide range of epidemiological risk factors and encompassing not just acne presentation, but also severity and scarring. The findings of from our study have provided further support to the existing evidence for the role of familial history and dietary habits in acne occurrence.

\section{Conclusions}

In conclusion, positive familial history is a strong predisposing factor in influencing acne presentation, severity and scarring among Malaysian Chinese. Frequent consumption of foods that are commonly consumed during breakfast (butter, probiotic drinks, cereals and milk) is protective against presenting with acne and having higher acne scarring grades, while alcohol drinking habit is a predisposing risk factor for acne among Malaysian Chinese. The predisposing risk factors revealed in this study can help researchers and clinicians to understand the epidemiology and pathophysiology of acne, and hence develop effective interventions especially targeting modifiable factors like dietary habits and lifestyle factors.

\section{Abbreviations}

BMI: Body mass index; Cl: Confidence interval; Gl: Glycaemic index;

GL: Glycaemic load; OR: Odds ratio; SD: Standard deviation

\section{Supplementary Information}

The online version contains supplementary material available at https://doi. org/10.1186/s12889-021-10681-4.

\section{Additional file 1.}

\section{Acknowledgements}

We would like to thank all participants for willing to participate in this study.

\section{Authors' contributions}

F.T.C. conceived and supervised the study. Y.-H.S. and A.H.S.H conducted the literature review process, analyzed the data, and wrote the manuscript. K.R., Y.R.W., K.F.T., S.M.R.S., Y.Y.S., Y.T.N., S.A.M. and S.L.P. recruited participants for the study. All authors reviewed and approved the manuscript.

\section{Funding}

F.T.C. has received research support from the Singapore Ministry of Education Academic Research Fund, Singapore Immunology Network, National Medical Research Council (NMRC) (Singapore), Biomedical Research Council (BMRC) (Singapore), and the Agency for Science Technology and Research (A*STAR) (Singapore); Grant Numbers: N-154-000-038-001; R-154000-404-112; R-154-000-553-112; R-154-000-565-112; R-154-000-630-112; R154-000-A08-592; R-154-000-A27-597; BMRC/01/1/21/18/077; BMRC/04/1/21/ 19/315; SlgN-06-006; SlgN-08-020; NMRC/1150/2008, and H17/01/a0/008. K.R. received research support from the Sunway University Grants INT-2019-SSTDBS-06 and STR-RMF-T20-005-2019. The funding agencies had no role in the study design, data collection and analysis, decision to publish, or preparation of the manuscript.

\section{Availability of data and materials}

All data used and included in this study are available from the corresponding author (F.T.C.) on reasonable request.

\section{Declarations}

Ethics approval and consent to participate

Ethical approval was granted from the Scientific and Ethical Review Committee (SERC) of UTAR (Ref. code: U/SERC/03/2016) and Sunway University Research Ethics Committee (Ref. code: SUREC 2019/029). All participants (or parent/guardian for those below 21 years) signed informed consent forms, and the study was conducted in accordance with the Declaration of Helsinki. 


\section{Consent for publication}

Not applicable.

\section{Competing interests}

F.T.C. reports grants from Singapore Ministry of Education Academic Research Fund, Singapore Immunology Network, National Medical Research Council (NMRC) (Singapore), Biomedical Research Council (BMRC) (Singapore), and the Agency for Science Technology and Research (A*STAR) (Singapore), during the conduct of the study; and consulting fees from Sime Darby Technology Centre; First Resources Ltd.; Genting Plantation, and Olam International, outside the submitted work. Y.-H. S., A. H. S. H., K. R., Y. R. W., K. F. T., S. M. R. S., Y. Y. S., Y. T. N., S. A. M., S. L. P. declare no conflict of interest.

\section{Author details}

'Department of Biological Sciences, Faculty of Science, National University of Singapore, Allergy and Molecular Immunology Laboratory, Lee Hiok Kwee Functional Genomics Laboratories, Block S2, Level 5, 14 Science Drive 4, Lower Kent Ridge Road, Singapore 117543, Singapore. ${ }^{2}$ Department of Biological Sciences, School of Medical and Life Sciences, Sunway University, 47500 Petaling Jaya, Selangor, Malaysia.

Received: 30 November 2020 Accepted: 23 March 2021

Published online: 27 March 2021

\section{References}

1. Vos T, Flaxman AD, Naghavi M, Lozano R, Michaud C, Ezzati M, et al. Years lived with disability (YLDs) for 1160 sequelae of 289 diseases and injuries 1990-2010: a systematic analysis for the global burden of disease study 2010. Lancet. 2012;380(9859):2163-96. https://doi.org/10.1 016/S0140-6736(12)61729-2.

2. Stathakis $V$, Kilkenny $M$, Marks R. Descriptive epidemiology of acne vulgaris in the community. Australas J Dermatol. 1997;38(3):115-23. https://doi.org/1 0.1111/j.1440-0960.1997.tb01126.x.

3. Cunliffe WJ. Acne and unemployment. Br J Dermatol. 1986;115(3):386 https://doi.org/10.1111/j.1365-2133.1986.tb05757.x.

4. Motley RJ, Finlay AY. How much disability is caused by acne? Clin Exp Dermatol. 1989;14(3):194-8. https://doi.org/10.1111/j.1365-2230.1989. tb00930.x.

5. Williams HC, Dellavalle RP, Garner S. Acne vulgaris. Lancet. 2012;379(9813): 361-72. https://doi.org/10.1016/S0140-6736(11)60321-8.

6. Mahto A. Acne vulgaris. Medicine (Baltimore). 2017;45(6):386-9. https://doi. org/10.1016/j.mpmed.2017.03.003.

7. Dréno B, Poli F, Pawin H, Beylot C, Faure M, Chivot M, et al. Development and evaluation of a global acne severity scale (GEA scale) suitable for France and Europe: global acne assessment scale. J Eur Acad Dermatol Venereol. 2011;25(1):43-8. https://doi.org/10.1111/j.1468-3083.2010.03685.x.

8. Goodman GJ, Baron JA. Postacne scarring: a qualitative global scarring grading system. Dermatol Surg. 2006;32(12):1458-66. https://doi.org/1 0.1111/j.1524-4725.2006.32354.x.

9. Heng AHS, Chew FT. Systematic review of the epidemiology of acne vulgaris. Sci Rep. 2020;10(1):5754. https://doi.org/10.1038/s41598-020-62 715-3.

10. Ismail NH, Manaf ZA, Azizan NZ. High glycemic load diet, milk and ice cream consumption are related to acne vulgaris in Malaysian young adults: a case control study. BMC Dermatol. 2012;12(1):13. https://doi.org/10.11 86/1471-5945-12-13.

11. Suppiah TSS, Sundram TKM, Tan ESS, Lee CK, Bustami NA, Tan CK. Acne vulgaris and its association with dietary intake: a Malaysian perspective. Asia Pac J Clin Nutr. 2018;27(5):1141-5.

12. Hanisah A, Omar K, Shah SA. Prevalence of acne and its impact on the quality of life in school-aged adolescents in Malaysia. J Prim Health Care. 2009;1(1):20-5. https://doi.org/10.1071/HC09020.

13. Muthupalaniappen L, Tan HC, Puah JWD, Apipi M, Sohaimi AE, Mahat NF, et al. Acne prevalence, severity and risk factors among medical students in Malaysia. Clin Ter. 2014;165(4):187-92. https://doi.org/10.7417/CT.2014.1731.

14. Ellwood P, Asher M, Ellwood E. Global asthma network steering group. Manual for global surveillance: prevalence, severity and risk factors. Auckland, New Zealand: Global Asthma Network Data Centre; 2015.

15. Zuraimi MS, Tham KW, Chew FT, Ooi PL, David K. Home exposures to environmental tobacco smoke and allergic symptoms among young children in Singapore. Int Arch Allergy Immunol. 2008;146(1):57-65. https:// doi.org/10.1159/000112503.

16. Vashi NA, Kundu RV. Facial hyperpigmentation: causes and treatment. Br J Dermatol. 2013;169:41-56. https://doi.org/10.1111/bjd.12536.

17. Common JEA, Barker JN, Steensel MAM. What does acne genetics teach us about disease pathogenesis? Br J Dermatol. 2019;181(4):665-76. https://doi. org/10.1111/bjd.17721

18. Karciauskiene J, Valiukeviciene S, Gollnick H, Stang A. The prevalence and risk factors of adolescent acne among schoolchildren in Lithuania: a crosssectional study. J Eur Acad Dermatol Venereol. 2014;28(6):733-40. https:// doi.org/10.1111/jdv.12160.

19. Aksu AE, Metintas S, Saracoglu ZN, Gurel G, Sabuncu I, Arikan I, et al. Acne: prevalence and relationship with dietary habits in Eskisehir, Turkey: acne prevalence and dietary habits. J Eur Acad Dermatol Venereol. 2012;26(12): 1503-9. https://doi.org/10.1111/j.1468-3083.2011.04329.x.

20. Al Hussein SM, Al Hussein H, Vari CE, Todoran N, Al Hussein H, Ciurba A, et al. Diet, smoking and family history as potential risk factors in acne vulgaris - a community-based study. Acta Medica Marisiensis. 2016;62(2): 173-81. https://doi.org/10.1515/amma-2016-0007.

21. Kaminsky A, Florez-White M, Bagatin E, Arias MI. The Iberian Latin American acne studies group (GILEA - Grupo Ibero-Latinoamericano de Estudio del acne). Large prospective study on adult acne in Latin America and the Iberian Peninsula: risk factors, demographics, and clinical characteristics. Int J Dermatol. 2019;58(11):1277-82. https://doi.org/10.1111/ijd.14441.

22. Adebamowo CA, Spiegelman D, Danby FW, Frazier AL, Willett WC, Holmes MD. High school dietary dairy intake and teenage acne. J Am Acad Dermatol. 2005;52(2):207-14. https://doi.org/10.1016/j.jaad.2004.08.007.

23. Adebamowo CA, Spiegelman D, Berkey CS, Danby FW, Rockett HH, Colditz $\mathrm{GA}$, et al. Milk consumption and acne in adolescent girls. Dermatol Online J. 2006;12(4):1.

24. Adebamowo CA, Spiegelman D, Berkey CS, Danby FW, Rockett HH, Colditz GA, et al. Milk consumption and acne in teenaged boys. J Am Acad Dermatol. 2008;58(5):787-93. https://doi.org/10.1016/j.jaad.2007.08.049.

25. Kaymak Y, Adisen E, Ilter N, Bideci A, Gurler D, Celik B. Dietary glycemic index and glucose, insulin, insulin-like growth factor-l, insulin-like growth factor binding protein 3, and leptin levels in patients with acne. J Am Acad Dermatol. 2007;57(5):819-23. https://doi.org/10.1016/j.jaad.2007.06.028.

26. Smith RN, Mann NJ, Braue A, Mäkeläinen H, Varigos GA. A low-glycemicload diet improves symptoms in acne vulgaris patients: a randomized controlled trial. Am J Clin Nutr. 2007;86(1):107-15. https://doi.org/10.1093/a jen/86.1.107.

27. Smith RN, Braue A, Varigos GA, Mann NJ. The effect of a low glycemic load diet on acne vulgaris and the fatty acid composition of skin surface triglycerides. J Dermatol Sci. 2008;50(1):41-52. https://doi.org/10.1016/j. jdermsci.2007.11.005.

28. Skroza N, Tolino E, Semyonov L, Proietti I, Bernardini N, Nicolucci F, et al. Mediterranean diet and familial dysmetabolism as factors influencing the development of acne. Scand J Public Health. 2012;40(5):466-74. https://doi. org/10.1177/1403494812454235.

29. Kober M-M, Bowe WP. The effect of probiotics on immune regulation, acne, and photoaging. Int J Womens Dermatol. 2015;1(2):85-9. https://doi.org/1 0.1016/j.ijwd.2015.02.001

30. Jung JY, Yoon MY, Min SU, Hong JS, Choi YS, Suh DH. The influence of dietary patterns on acne vulgaris in Koreans. Eur J Dermatol EJD. 2010;20(6): 768-72. https://doi.org/10.1684/ejd.2010.1053.

31. Rombouts S, Nijsten T, Lambert J. Cigarette smoking and acne in adolescents: results from a cross-sectional study. J Eur Acad Dermatol Venereol. 2007;21(3):326-33. https://doi.org/10.1111/j.1468-3083.2006.01 915.x.

32. Karadağ AS, Balta I, Saricaoğlu H, Kiliç S, Kelekçi KH, Yildirim M, et al. The effect of personal, familial, and environmental characteristics on acne vulgaris: a prospective, multicenter, case controlled study. G Ital Dermatol Venereol. 2019; 154(2):177-85. https://doi.org/10.23736/S0392-0488.17.05532-8.

33. Schafer T, Nienhaus A, Vieluf D, Berger J, Ring J. Epidemiology of acne in the general population: the risk of smoking. Br J Dermatol. 2001;145(1):1004. https://doi.org/10.1046/j.1365-2133.2001.04290.x.

34. Di Landro A, Cazzaniga S, Cusano F, Bonci A, Carla C, Musumeci ML, et al. Adult female acne and associated risk factors: Results of a multicenter casecontrol study in Italy. J Am Acad Dermatol. 2016;75(6):1134-1141.e1.

35. Wolkenstein P, Misery L, Amici J-M, Maghia R, Branchoux S, Cazeau C, et al. Smoking and dietary factors associated with moderate-to-severe acne in 
French adolescents and young adults: results of a survey using a representative sample. Dermatology. 2015;230(1):34-9. https://doi.org/10.11 59/000366195.

36. Wolkenstein P, Machovcová A, Szepietowski JC, Tennstedt D, Veraldi S, Delarue A. Acne prevalence and associations with lifestyle: a cross-sectional online survey of adolescents/young adults in 7 European countries. J Eur Acad Dermatol Venereol. 2018;32(2):298-306. https://doi.org/10.1111/jdv.14475.

37. Hogewoning AA, Koelemij I, Amoah AS, Bouwes Bavinck JN, Aryeetey Y, Hartgers $F$, et al. Prevalence and risk factors of inflammatory acne vulgaris in rural and urban Ghanaian schoolchildren. Br J Dermatol. 2009;161(2):475-7. https://doi.org/10.1111/j.1365-2133.2009.09259.x.

38. Park SY, Kwon HH, Min S, Yoon JY, Suh DH. Epidemiology and risk factors of childhood acne in Korea: a cross-sectional community based study. Clin Exp Dermatol. 2015;40(8):844-50. https://doi.org/10.1111/ced.12686.

39. Lu L, Lai H, Pan Z, Wu Z, Chen W, Ju Q. Obese/overweight and the risk of acne vulgaris in Chinese adolescents and young adults. Hong Kong J Dermatolology Venereol. 2017;25(1):5-12.

40. Silverberg Jl, Silverberg NB. Epidemiology and extracutaneous comorbidities of severe acne in adolescence: a U.S. population-based study. Br J Dermatol. 2014;170(5):1136-42. https://doi.org/10.1111/bjd.12912.

41. Bhate K, Williams HC. Epidemiology of acne vulgaris: epidemiology of acne vulgaris. Br J Dermatol. 2013;168(3):474-85. https://doi.org/10.1111/bjd.12149.

\section{Publisher's Note}

Springer Nature remains neutral with regard to jurisdictional claims in published maps and institutional affiliations.

Ready to submit your research? Choose BMC and benefit from:

- fast, convenient online submission

- thorough peer review by experienced researchers in your field

- rapid publication on acceptance

- support for research data, including large and complex data types

- gold Open Access which fosters wider collaboration and increased citations

- maximum visibility for your research: over $100 \mathrm{M}$ website views per year

At $\mathrm{BMC}$, research is always in progress.

Learn more biomedcentral.com/submissions 